\section{Amniotic fluid embolism}

To the Editor:

I was interested to read the clinical report by Davies titled 'Amniotic fluid embolism and isolated disseminated intravascular coagulation'. ${ }^{1}$ The author concludes that the diagnosis of amniotic fluid embolism was 'primarily clinical and one of exclusion'. However, from personal experience of managing a survivor case of amniotic fluid embolism, I would suggest that in the setting of gravid hysterectomy the histopathologist can often confirm the diagnosis.

The postmortem diagnosis of an amniotic fluid embolism is made by demonstration of amniotic fluid debris in the pulmonary vasculature. The same findings in the blood vessels of the uterus and in particular the cervix ${ }^{2}$ also confirm the diagnosis in survivors.

The diagnosis can also be made by cytological examination of blood from central venous or pulmonary catheterization. ${ }^{3}$ However, the presence of squames alone is not pathognomonic ${ }^{4}$ but often the result of contamination.

Several other diagnostic methods are described in the literature. One example is measurement of maternal plasma zinc coproporphyrin. ${ }^{5}$ This is a component of meconium.

Mark Bannister MB CHB MRCGP FRCA

Cardiff, Wales

References

1 Davies S. Amniotic fluid embolism and isolated disseminated intravascular coagulation. Can J Anesth 1999; 46: 456-9.

2 Cheung AN, Luk SC The importance of extensive sampling and examination of cervix in suspected cases of amniotic fluid embolism. Arch Gynecol Obstet 1994; 255: 101-5.

3 Kublman K, Hidvegi D, Tamura RK, Depp R Is amniotic fluid material in the central circulation of peripartum patients pathologic? Am J Perinatol 1985; 2: 295-9.

4 Lee W, Ginsburg KA, Cotton DB, Kaufman RH Squamous and trophoblastic cells in the maternal pulmonary circulation identified by invasive hemodynamic monitoring during the peripartum period. Am J Obstet Gynecol 1986; 155: 999-1001.

5 Kanayama N, Yamazaki T, Naruse H, Sumimoto K, Horiuchi $K$, Terao T. Determining zinc coproporphyrin in maternal plasma - a new method for diagnosing amniotic fluid embolism. Clin Chem 1992; 38: $526-9$.
REPLY:

Although several diagnostic tests have been suggested, at the present time there is no routine diagnostic scheme that will easily and reliably confirm the presence of an amniotic fluid embolus (AFE) in suspected cases. Part of the difficulty is that clinical availability and experience with some of the more recent tests is lacking. In regards to the presence of fetal debris in the maternal vasculature, either centrally or peripherally, I agree with $D r$. Bannister that such a finding is highly supportive of the diagnosis and clinicians should be encouraged to seek such evidence. Unfortunately, partly because of a lack of communication between pathologists and clinicians, the required sampling is not always done or the appropriate stains are not utilized. ${ }^{1}$ Moreover, since amniotic fluid embolus is presently considered to be a whole spectrum of disease ranging from a subclinical entity to one that is rapidly fatal, obtaining central access may not always be clinically indicated or feasible. In those cases where pulmonary artery catheterization is obtained, contamination of the sample by maternal cells can be minimized by utilizing the method suggested by Masson. ${ }^{2}$ The demonstration of fetal debris in such a sample is highly significant and consistent with the diagnosis. However, it is important to remember that although such a finding is supportive, it is not necessary for the diagnosis. Until simple, less invasive methods of confirming the diagnosis are validated and become readily available, the diagnosis remains one of exclusion, based on a compatible clinical presentation and careful elimination of all other diagnostic possibilities.

Sharon Davies MD FRCPC

Toronto, Ontario

References

1 Clark SL. New concepts of amniotic fluid embolism. A review. Obstet Gynecol Surv 1990; 445: 360-8.

2 Masson RG Amniotic fluid embolism. Clini Chest Med 1992; 13: 657-65.

\section{Perioperative core temperature}

To the Editor:

Kamitani et al., ${ }^{1}$ in their study on perioperative core temperature, are to be congratulated on preventing core hypothermia and thus the potential complications i.e. myocardial ischemia; shivering; impaired wound healing, immunity and coagulation; prolonged hospital stay. 
However, I think the title of the paper and conclusion reached were misleading. The conclusion that "covering the patients head and face maintains intra operative core temperature" implies that performing this sole step prevents core hypothermia. This was not true. The patients were also wrapped in aluminium sheets and had surgery in a relatively warm ambient temperature; both these steps help to prevent heat loss. $^{2,3}$ Another important omission was that it was not stated whether intravenous fluids were warmed to body temperature, another excellent strategy for preventing hypothermia. ${ }^{4}$

I suspect that the reason why neither group of patients developed core hypothermia was that both groups of patients were well covered up anyway, the ambient temperature was relatively high, and the iv fluids may well have been warmed. The correct conclusion is that covering the head and face as well as the limbs/chest/pelvis, undergoing surgery in a warm ambient temperature, and warming iv fluids retards the development of core hypothermia.

John Esmond

Toronto, Ontario

References

1 Kamitani K, Higuchi A, Takebayashi T, Miyamoto $\Upsilon$, roshida $H$. Covering the head and face maintains intra operative core temperature. Can J Anesth 1999; 46: 649-52.

2 Frank SM, Beattie C, Christopherson R, et al. Epidural versus general anesthesia, ambient operating room temperature, and patient age as predictors of inadvertent hypothermia. Anesthesiology 1992; 77: 252-7.

3 Hindsholm KB, Bredabl C, Herlevsen P, Kruhoffer PK.

Reflective blankets used for reduction of heat loss during regional anaesthesia. Br J Anaesth 1992; 68: 531-3.

4 Smith CE, Desai R, Glorioso V, Cooper A, Pinchak AC, Hagen $K F$. Preventing hypothermia: convective and intravenous fluid warming versus convective warming alone. J Clin Anesth 1998; 10: 380-5. 